\title{
REVIEW ON ANALYTICAL STUDY ON STRENGTHENING OF BEAM
}

\section{BY FRP}

\author{
K.B.Parikh ${ }^{1}$, N.S.Patel ${ }^{2}$ \\ ${ }^{1}$ Assistant Professor, Department of Applied Mechanics, Government Engineering College, Dahod-389151 \\ ${ }^{2} P G$ student, Government Engineering College, Dahod-389151 \\ Email ID: nirav7441@gmail.com
}

\begin{abstract}
This paper present the review of analytical and numerical study of flexural and shear performance of retrofitted or strengthening of beam by fibre reinforced polymer (FRP). Now a day investigator prefer numerical and analytical study to minimize error which can't reduce in experimental study, hence numerical study is more reliable than experimental study and analytical study less time consuming then experimental still having good agreement with experimental study. Almost all the software available in market are work based on finite element method (FEM) such as ANSYS, ATENA 3D and ABAQUS. Analytical study carried out by different author using FEM basedsoftware they found ultimate capacity of beam increased noticeably.Analytical investigation of reinforced concrete $(R C)$ beam with FRP were carried out by number of investigator they all studied on different aspect, some of those worked on single layer or double layer of FRP, some of those worked on different pattern and thickness of FRP and then compared stress, strain and deflection with control specimen. For precise result by finite element method use fine mashing and appropriate material property. Bond behaviour between steel-concrete and concrete-FRP sheets/plate must be specify for accurate and realistic results.
\end{abstract}

Keywords: retrofitting of beam, strengthening of beam, GFRP, CFRP, Finite Element Method (FEM), ANSYS

\section{INTRODUCTION}

Reinforce concrete beam can be retrofitting by FRP (Fiber Reinforced Polymer) are one of the effective technique of retrofit of beam. Retrofitting of beam by FRP popular now a days cause low material cost, light weight, corrosion free and easy of application. Number of FRP available in currant market namely Carbon Fibre Reinforced Polymer (CFRP), Glass Fibre Reinforced Polymer (GFRP) And Kevlar Fibre Reinforced Polymer (KFRP). FRP are available in three form such as plates, sheets and bars. By application of FRP not only flexure strength but shear strength are extensively increased. FRP plate/ sheets adhesively bonded to the bottom face of simply supported beamfor increase in flexure strength and bonded to the side face of the beam for increase in shear strength. Obviously bending moment highest in middle of the beam so for increase in flexural strength FRP apply middle of the beams but in actual practice the FRP sheets apply throughout beam to avoid debonding of sheets.FRP widely accepted because comparatively low cast, high strength, corrosion resistance and high fatigue resistance. GFRP are widely accepted for their cheap rate over carbon fibre composites still CFRP used were strength, stiffness and ductility were necessary. Researcher carried out experimental, numerical and analytical study to understand the behaviour of FRP in beam. Analytical results good agreement with experimental results ${ }^{[1]}$. At the same time some of the researcher focused on recognize and understand the failure modes that reinforced concrete beams retrofitted with FRP. The principle failure modes experimentally identified that was flexure and shear failure of concrete and debonding of FRP.
For structural application, we can use FRP in two ways. First ways we can use FRP as a sheet or plate which is to strengthen damage structural member by application of FRP. Retrofitting and strengthening structure member such as beam, column and slab with external application of FRP are an one of the effective method use over a world. Second way we can use FRP as a bars in reinforced concrete member instead of steel bar.

\section{LITERATURE REVIEW}

P.Parandaman ${ }^{[1]}$ et al worked on RC structure which is damaged during earthquake and they tried to retrofitting of that reinforced structure with fibre reinforce composite. They presented paper on finite element analysis of beam retrofitted with different fibre reinforced polymer composite sheets carried out using ANSYS software. They applied GFRP, CFRP and KFRP on same size of beam and then author did modelling and analysis by ANSYS. Investigator's objective is to compare performance of above three retrofitted beams with controlled beam. Author finally concluded from the ANSYS results, deflection of the retrofitted beam with CFRP is minimized about $73 \%$ compared to controlled beam, deflection of the retrofitted beam with GFRP is minimized about $65 \%$ compared to controlled beam, deflection of the retrofitted beam with KFRP is minimized about $60 \%$ compared to controlled beam and load carrying capacity of retrofitted beam is higher than the controlled RC beam specimen.

Tarek H. Almusallam ${ }^{[2]}$ et al study on strengthened or repaired reinforced concrete specimens. Strengthening of 
RC beam achieved by application of glass fiber reinforced polymer (GFRP) to the bottom face of the beam. They compared flexural capacity and mid span of the strengthened beams and control beams to evaluate effectiveness of strengthening technique. Author investigated on twelve beams and size of the beam is 150 X 200 X $2050 \mathrm{~mm}$. They were applied FRP on beam three different way. In the first group author applied FRP at bottom of the beam, second group they applied FRP used $u$ shaped sheet and in third group then applied double layer of FRP at the bottom of the beam. They used Amsler testing machine for application of load and for find out central deflection they used linear variable displacement transducer (LVTD). Author performed test on that beam and finally conclude that flexural strength increased considerably by bonding GFRP sheets to the bottom face of the reinforced concrete beams and $U$ shaped anchorage system had considerable effected on ultimate strength and failure mode of the beam. Author also observed that to improve ductility and strength a GFRP is one of the effective solution.

Kaushal Parikh ${ }^{[3]}$ et al carried out experimental and analytical investigation on preloaded retrofitted beam with GFRP for enhancement in flexural strength. They took seventeen beam for experimental study, out of that two were control beams and fifteen were preloaded at $0 \%, 40 \%$ and $90 \%$ of control beam. Author used new arrangement of FRP for strengthening the beam in which they were apply full length of single layer, they reduced length and width in second and third layer. Author also carried out analytical investigation using ATENA 3D software which are based on finite element method. Author concluded from the analytical and experimental results, new arrangement so effective that was shift the flexural crack away from the flexural region and also come out from the debonding failure. They observed load vs. deflection not more than $5 \%$ varied in experimental and analytical results, failure mode are also remarkable compared.

F.A.Fathelbab ${ }^{[4]}$ et al conducted analytical investigation on strengthened RC simple beam with externally bonded FRP sheets technique, that's beam was loaded in flexure, shear and a combination of flexure and shear. Author used ANSYS software to perform structure linear and non-linear analysis. Author studied main parameter control beam of different schemes of FRP sheets in flexural, shear and combination flexural and shear. Investigator compared that results and conclude that beam capacity and ductility directly proportional to CFRP sheets applied on the beam but at the same time author observed that the beam capacity didn't increased with increased in CFRP sheets but ductility did.

P. Jayajothi ${ }^{[5]}$ et al conducted ANSYS based analytical investigation on simulate behaviour of failure mode of RC beams strengthened in flexure and shear by Fibre reinforced polymer (FRP) laminate. Author carried out study on four beams model, from those two were control beams and remained was strengthened with CFRP. Author obtained load deflection relationship until failure and crack pattern by ANSYS and that result compared with experimental results available in literature. Author observed numerical result seen good agreement with experimental results. Based on analytical results author concluded that ultimate load carrying capacity was increased comparatively, flexural strength increased substantially while CFRP applied on tension face and load carrying capacity of beam strengthened by U-warp CFRP was found to be higher compared with CFRP applied on tension face only.

J. Lundqvist ${ }^{[6]}$ et al carried out study on anchorage length of FRP to effective strengthening of RC beam. Author did experimental work and analytical investigation by ABAQUS that's was based in finite element analysis. Author used three different type of strengthening technique such as bonded plates, sheets and the Near Surface Mounted Reinforcement (NSMR). Investigator aim to find out critical anchorage length, for that they were took different length that was 100, 200, and $500 \mathrm{~mm}$. from the experimental and analytical investigation author find out the failure load and strain in RC beam. Author conclude form the result the critical anchorage length was less the $200 \mathrm{~mm}$ for sheet, 200 $\mathrm{mm}$ for plate and anchorage length not very clearly understand in NSMR. Author also observed that increased in anchorage length added structural safety but does not increase in load carrying capacity.

Hsuan-Teh ${ }^{[7]} \mathrm{Hu}$ et al carried out numerical study by ABAQUS based on finite element method to predict the ultimate loading capacity of rectangular reinforced concrete beams strengthened by fibre reinforced plastics applied at the bottom or on side face of those beam. Author studied influences of fibre orientation, beam length and reinforcement ratio on the ultimate strength of the beam. Investigator conclude form the numerical result FRP strengthening is not effective for high reinforcement ratio as compared with low reinforcement ratio. Author observed more crack at the central region of the beam with high reinforcement ratio which was strengthened with FRP at the bottom, and found comparatively more crack at support area of the beam with low reinforcement ratio which was strengthened with FRP at the bottom. Author seen increased ultimate strength and deceased crack when FRP applied on bottom face of the beam.

Y.C. Wang and C.H. Chen ${ }^{[8]}$ studied on the RC tee beam with applied CFRP at tension face or bottom face of the beam and applied GFRP at side/shear face of beam. Author proposed model which was based on discrete element method. That was used to predict behaviour of load versus displacement and FRP plate bond stresses. Author concluded that model predicted of failure of strengthened beam in a more practical manner than other analytical models. Author observed model accurately predicted loaddisplacement behaviour and they was also found excellent agreement between measured plate strain and the strain predicted by model.

C. C. Spyrakos ${ }^{[9]}$ et al carried out experimental and analytical investigation of the effectiveness of FRP strengthening sheets on RC beams to increase their flexural strength and stiffness. Author conducted four point bending 
tests on four full scale reinforced concrete beams strengthened with externally bonded FRP. Author investigated the strength, deflection and failure mode strengthened beams in both experimentally and analytically. Form the results by the application of CFRP increased beam strength and stiffness. They were observed that different resin and anchorage system significantly influenced the resulting strength and stiffness of the specimen.

Sergio F. Bren and Beth M. Macri ${ }^{[10]}$ experimentally carried out tests on eighteen small scale reinforced concrete beam strengthened by CFRP composites. Author aimed to understand behaviour of strengthened reinforced concrete beams under different configuration of CFRP. Author used three different type of configuration, in first case laminates were attached only tension face of the beam, second case laminate were attached only shear/side face of the beam and for third case laminates were attached entire specimen or Ushape. They were used strain gauge in a region where crack in concrete were performed to monitor the variation of strains throughout testing. From the experiment they concluded composite pattern/configuration directly affect behaviour of load versus deflectio load and deflection of the beam were affected by composite configuration. Author observed local strain didn't provided a realistic representation of the globe beam behaviour.

Dhanu M.N ${ }^{[11]}$ et al carried out studied on experimental and numerical investigation of retrofitted reinforced concrete beams using Fibre Reinforced Polymer (FRP). They were used GFRP and Coir FRP for retrofitting of beam and compared performance between them. Experimental study involves the determination of flexural load by subjected three point loading. They calculated permissible load by usingproper factor of safety on ultimate load. They took that permissible load for numerical study. For numerical study of RC beams retrofitted with GFRP were considered and they used ANSYS 13 software to analysis of beams structure. They applied load was in the form of uniformly distributed load and they considered the beam was supported by fixed support at its ends. From the result of Experiment and Numerical study carried out by author, they conclude that the flexural strength and ultimate load capacity with same deflection of the beam can be improved by retrofitting. Author also observed load carrying capacity of RC beam was higher when they applied GFRP.

Ramesh Kumar U More ${ }^{[12]}$ et al investigated on flexural behaviour of Aramid fiber (Kevlar fiber) reinforced polymer (AFRP) used for strengthening reinforced concrete (RC) beams of $\mathrm{M}_{25}$ grade of concrete. Investigator took the beam size was $100 \times 150 \times 1200 \mathrm{~mm}$ and that was strengthened by Aramid fiber polymer sheets. Author studied on effect of strengthening on load carrying capacity and effect of damage degree. Author Used ANSYS software for validation of Experimental work and they found good agreement between analytical result and experimental result. They only work on flexural behaviour so beams were wrapped with AFRP sheets in single layer and double layers along the full length of beam at the bottom face. Author concluded from results that the ultimate load carrying capacity for $0 \%$ damage degree beams were increased after strengthened with single layer and double layer of $100 \mathrm{~mm}$ width AFRP strip was $27.59 \%$ and $49.27 \%$ respectively compared with controlled beam, ultimate load carrying capacity were increased with increased in layer of AFRP strip, with increased in degree of damage, deflection at ultimate load was found to be decreasing by applying AFRP strip and $0 \%, 70 \%$, and $80 \%$ damaged degree beams showed higher performance in terms of load carrying capacity, while $90 \%$ and $100 \%$ damage degree beams did not show appreciable increased in load carrying capacity.

Dr.D.L.Venkatesh babu ${ }^{[13]}$ et al investigated behaviour of FRP beams. Author calculated banding moment, the model considers an exponential function in the stress-strain diagram of $\mathrm{RC}$ in both tension and compression parallel to the fibre. Author conducted four point loading test to determineload versus displacement relationship of RC beam with GFRP and CFRP sheets adhered to the tension face/bottom face. Author used finite elementtechnics to understand best warping style for retrofitting the deficient beamsand they also study of effectiveness of CFRP/GFRP sheets in flexure strength of RC beams. From the results, author conclude that general behaviours of the finite models show good agreement with experimental results of beam test.Also form the result obtained by author that demonstrated that CFRP was more efficient than GFRP in strengthening the reinforced concrete beams for shear.

\section{CRITICAL REMARKS}

Following conclusion are made from above literature review:-

1. Application of FRP on RC beam increases flexure and shear strength considerably.

2. Most of the investigator conducted study on rectangle beam for flexural and shear strengthening with different type of FRP with constant thickness of GFRP and which are strengthened with one, two and three layer of FRP without curtailment and they found strength increased with increased in layer but in decreasing manner.

3. Carbon reinforced polymer are more effective in flexure and shear performance than glass fibre reinforced polymer.

4. Analytical study based on finite element method have a good agreement with experimental study.

5. The final load/ ultimate load from the FEM are higher than experimental results but load vs. deflection behaviour is almost similar.

6. Numerical study can be used to predict the behaviour of retrofitted reinforced concrete beams more precisely by assigning appropriate material properties and appropriate connection between concrete and FRP.

7. Analytical result may be higher because bond behaviour between FRP and concrete are not cleared.

8. Toughness and ductility were increased noticeably of RC beam which strengthened with FRP.

9. All the investigator took arbitrary thickness of FRP especially who carried out analytical study. 
10. Design guideline not available for optimizing and choosing the thickness of FRP sheets/laminate for strengthening of RC beams.

11. Failure mode of debonding of FRP cannot properly understand in analytical study.

12. By applying appropriate pattern of FRP application the performance of RC beams may increase considerable.

13. Anchorage length affects the strength and failure mode of RC beam

\section{REFERENCES}

[1] P.Parandaman and M.Jayaraman, Finite element analysis of reinforcement concrete beam retrofitted with different fibre composites, Middle-East Journal of Scientific Research, 2014, pp 948-52.

[2] Tarek H. Almusallam and Yousef A. Al-Salloum, Ultimate strength prediction of RC beams externally strengthened by composite materials, composite engineering, Feb-2001, Part-B, pp 609-19.

[3] Kaushal Parikh and C.D.Modhera, Application of GFRP on preloaded retrofitted beam for enhancement in flexural strength, International Journal of Civil and Structural Engineering, May-2012, pp 1070-80.

[4] F.A.Fathelbab, M.S.Ramadan and A. Al-Tantawy, Finite element modelling of strengthened simple beams using FRP techniques: A parametric study, Concrete Research Letters, June-2011, Volume-2, pp 228-40.

[5] P.Jayajothi, R Kumutha and K. Vijai, finite element analysis of FRP strengthened RC beams using ANSYS, Asian Journal of Civil Engineering, 2013, Volume-14, pp 631-42.

[6] J. Lundqvist, H. Nordin, B. Täljsten and T. Olofsson, Numerical analysis of concrete beams strengthened with CFRP- a study of anchorage lengths, 2005, International Institute for FRP in Construction.

[7] Hsuan-Teh Hu, Fu-Ming Lin and Yih-Yuan Jan, Nonlinear finite element analysis of reinforced concrete beams strengthened by fiber-reinforced plastics, 2004, Composite Structure, pp 271-81.

[8] Y.C. Wang, C.H. Chen, Analytical study on reinforced concrete beams strengthened for flexure and shear with composite plates, 2003, Composite Structure, pp 13748.

[9] C.C. Spyrakos, I.G. Raftoyiannis, L. Credali and J. Ussia, Experimental and Analytical Study on Reinforced Concrete Beams in Bending Strengthened with FRP, 2014, The Open Construction and Building Technology Journal, pp 153-63.

[10]Sergio F. Bren, Beth M. Macri, Effect of Carbon-FiberReinforced Polymer Laminate Configuration on the Behavior of Strengthened Reinforced Concrete Beams, May-June 2004, Journal of Composites for Construction, pp 229-40.

[11]Dhanu M.N , Revathy D, Lijina Rasheed and Shanavas $\mathrm{S}$, Experimental and numerical study of retrofitted RC beams using FRP, International Journal of Engineering Research and General Science, April-May 2014, Volume-2, pp 383-90.

[12]Rameshkumar U More and D.B.Kulkarni, Flexural behaviour study on RC beam with externally bonded aramid fibre reinforced polymer, International Journal of Research in Engineering and Technology Jul-2014, Volume-03, pp 316-321.

[13]A.Vijayakumar, Dr.D.L.Venkatesh babu and R. Jayaprakash, Analytical study on various types of FRP beams by using AVSYS, International Journal of Engineering Research and Applications, Sep-Oct 2012, Volume-2, pp 593-98. 